\title{
Starch Degradation of Detached Apple Fruit in Relation to Ripening and Ethylene
}

\author{
Manasikan Thammawong and Osamu Arakawa* \\ Faculty of Agriculture and Life Science, Hirosaki University, Bunkyocho, Hirosaki 036-8561, Japan
}

\begin{abstract}
The physiology of starch degradation in relation to ripening and ethylene was investigated using 'Tsugaru' (earlymaturing) and 'Fuji' (late-maturing) apples (Malus domestica Borkh.). Fruits were harvested at immature and mature stages, and treated with ethylene and 1-methylcyclopropene (1-MCP). In immature fruit of both cultivars, starch content rapidly decreased during storage at $25^{\circ} \mathrm{C}$, and 1-MCP had little effect on this change. Ethylene treatment slightly stimulated the degradation of starch, but differences in starch among treatments were small. The respiration rate gradually decreased and ethylene production remained low during storage irrespective of the treatments and cultivars. These results showed that fruit at this stage could not respond to endogenous and exogenous ethylene for inducing the climacteric, and starch degradation did not relate to the climacteric or ethylene. In mature 'Tsugaru', 1-MCP treatment significantly inhibited ethylene production and reduced the respiration rate and starch degradation. The effects of 1-MCP and ethylene on starch degradation in mature 'Fuji' were small, and starch content decreased drastically in all treatments, although 1-MCP significantly inhibited ethylene production and the respiration rate. It is suggested that ethylene is partially involved in starch degradation in mature 'Tsugaru', but not in 'Fuji'. These results showed that the role of ethylene in starch degradation differs between cultivars and their harvested stages, relating to ripening and physiological characteristics of the fruit.
\end{abstract}

Key Words: 1-methylcyclopropene (1-MCP), apple, ethylene, Malus domestica Borkh., starch degradation.

\section{Introduction}

Starch is the primary carbohydrate in unripe fruit. As fruit ripens, starch is degraded, and the sugar content (soluble solid concentration) increases, providing the sweetness associated with the taste of ripe fruit (Blankenship and Unrath, 1988; Brookfield et al., 1997; Dinar and Stevens, 1981; Prabha and Bhagyalakshmi, 1998). Additionally, sweetness is one of the important attributes in apples, affecting the final flavor and increasing the fruit quality and its price; therefore, starch accumulation during growth, and starch degradation during ripening are important phenomena.

The net loss of starch starts at the beginning of the fruit ripening process on and off the tree (Brookfield et al., 1997; Lau, 1988; Magein and Leurquin, 2000). After harvesting apple fruit, a rapid increase in ethylene production and the respiration rate of the fruit is simultaneously observed with the loss of the starch content. In addition, ethylene has been suggested to be involved in stimulating the conversion of starch to sugar

Received; November 27, 2006. Accepted; June 11, 2007.

* Corresponding author (E-mail: oarakawa@cc.hirosaki-u.ac.jp).
(Kader, 1985; Watkins, 2003); however, Blankenship and Unrath (1988) reported that the starch conversion process of 'Golden Delicious' was independent of ethylene production. While there are some studies of the physiology of starch degradation, the relationship between starch degradation and other physiological changes, such as respiration and ethylene production, is still unclear. Moreover, further research is required to clarify the role of ethylene in starch degradation during the development of apple fruit.

The ethylene action inhibitor, 1-methylcyclopropene (1-MCP) (Sisler and Serek, 1997), has been shown to increase post-harvest life and maintain fruit quality. It delays ethylene production and the respiration rate, maintains fruit firmness, and reduces the loss of starch content in apples (Fan et al., 1999; Pre-Aymard et al., 2003). Although there are studies showing that 1-MCP might have inhibitory effects on the starch degradation process during ripening by blocking ethylene action, there is still debate about the effect of 1-MCP on the starch metabolism of apple fruit.

The objective of this study was to investigate the physiology of starch degradation in relation to ripening and ethylene in 'Tsugaru', which produces high amounts 
of ethylene, and 'Fuji', which produces very low amounts of ethylene.

\section{Materials and Methods}

Apple fruits

Two cultivars of apples, early-maturing 'Tsugaru' fruit from a 5-year-old tree and late-maturing 'Fuji' fruit from a 30-year-old tree grafted on Marubakaido (Malus prunifolia Borkh.) rootstock, were obtained from the experimental orchard of the Faculty of Agriculture and Life Science, Hirosaki University, Japan. Fruits of each cultivar were harvested at two maturing stages. Immature fruits were harvested at 70 days after full bloom (DAFB) for 'Tsugaru' and 116 DAFB for 'Fuji'. Mature fruits were harvested at 106 DAFB for 'Tsugaru' and 148 DAFB for 'Fuji'. The fruits of each harvesting crop were separated into three groups for treatment with ethylene or 1-MCP, and a control.

\section{Treatments}

For ethylene treatment, pure ethylene gas $(2.8 \mathrm{~mL}, \mathrm{GL}$ Sciences Inc., Japan) was injected into a closed container (28 L) to produce a final concentration of $100 \mu \mathrm{L} \cdot \mathrm{L}^{-1}$ of ethylene. The container was then kept at $25^{\circ} \mathrm{C}$ for $24 \mathrm{~h}$. For 1-MCP treatment, $1 \mathrm{~g}$ of SmartFresh $(0.14 \%$ A.I., Rohm and Haas Co., Japan) powder was placed in a flask inside a container and $25 \mathrm{~mL}$ distilled water was then added with a syringe through the cap and a rubber hose into the flask, which produced $22.3 \mu \mathrm{L} \cdot \mathrm{L}^{-1}$ of $1-\mathrm{MCP}$. The fruit was treated with $1-\mathrm{MCP}$ at $25^{\circ} \mathrm{C}$ for $24 \mathrm{~h}$. After the treatments, all fruits were kept at $25^{\circ} \mathrm{C}$ in a storage room for ripening.

\section{Measurements}

\section{Physiological Analyses}

To determine $\mathrm{CO}_{2}$ production, each fruit was weighed and sealed in $1.4 \mathrm{~L}$ plastic boxes for $2 \mathrm{~h}$, and $1 \mathrm{~mL}$ of headspace gas was injected into a gas chromatograph (model GC-18A, Shimadzu Co., Ltd., Japan) equipped with a molecular sieve column (60/80 mesh, GL Sciences, Inc.), and a thermal conductivity detector. Helium was the carrier gas. The injector, oven, and detector temperatures were set at $60^{\circ} \mathrm{C}$. To determine the ethylene content, $1 \mathrm{~mL}$ of the headspace gas was removed and injected into a gas chromatograph (model GC-8A, Shimadzu Co., Ltd.) equipped with an activated alumina column (30/60 mesh, GL Sciences, Inc.) and flame ionization detector. Nitrogen was the carrier gas. The injector, oven, and detector temperatures were set at 120,100 , and $120^{\circ} \mathrm{C}$, respectively.

\section{Chemical Analysis}

The fruit flesh was sampled, immediately frozen in liquid nitrogen, and kept at $-80^{\circ} \mathrm{C}$ until starch analysis. The method of determination was that of Pharr and Sox (1984) and Wang et al. (1997). Briefly, $200 \mathrm{mg}$ of the sample was ground and extracted three times with $4 \mathrm{~mL}$ of $80 \%(\mathrm{v} / \mathrm{v})$ ethanol at $80^{\circ} \mathrm{C}$, each for $30 \mathrm{~min}$, and then the suspension was centrifuged. The remaining pellet was dried and used for starch determination. Two milliliters of $0.2 \mathrm{M} \mathrm{KOH}$ was added to the pellet and the suspension was boiled for $30 \mathrm{~min}$. After cooling to room temperature, the $\mathrm{pH}$ of the suspension was adjusted to 4.5 with $1 \mathrm{M} \mathrm{CH}{ }_{3} \mathrm{COOH}$ and then 600 units of amyloglucosidase from Aspergillus niger (EC 3.2.1.3) (Sigma Chemical Co., MO, USA) dissolved in $0.2 \mathrm{M}$ $\mathrm{NaAc}-\mathrm{HAc}$ buffer was added to hydrolyze the starch to glucose by incubation in a $55^{\circ} \mathrm{C}$ water bath for $1 \mathrm{~h}$. The reaction was stopped by immersing the sample tubes in boiling water for $10 \mathrm{~min}$, and the digest was then centrifuged. The supernatant was filtered, and injected into an HPLC for glucose determination. The HPLC was operated under the following conditions: column: SCR101C (7.9 I.D. $\times 300$ mm, Shimadzu LC, Shimadzu Co., Ltd.); mobile phase: water $0.5 \mathrm{~mL} \cdot \mathrm{min}^{-1}$; post column mixture: $1 \mathrm{M} \mathrm{NaOH}, 0.25 \mathrm{~mL} \cdot \mathrm{min}^{-1}$; column temperature: $80^{\circ} \mathrm{C}$, detector: PAD.

\section{Data analysis}

Analysis of Variance (ANOVA) with Completely Randomized Design (CRD) using chemical treatments as a factor was performed using SPSS (SPSS, IL, USA), and Tukey's multiple-range test was used to test significant difference at the $95 \%$ confidence level of each variable.

\section{Results}

\section{The effect of ethylene and 1-MCP on starch degradation in immature apple fruit}

The loss of starch content in immature 'Tsugaru' occurred over 4-day storage, and almost all of the starch in fruits of all treatments was degraded within 8-day storage. The starch content of ethylene-treated fruit was lower than the control on day 4 after harvest with significant difference $(P \leq 0.05)$; however, no difference in starch content between 1-MCP-treated fruit and the control was observed (Fig. 1A). The respiration rate decreased, remaining low during storage with no obvious differences among treatments (Fig. 1B). Ethylene production in fruits of all treatments was less than $0.005 \mu \mathrm{L} \cdot \mathrm{L}^{-1}$ during storage (data not shown).

In immature 'Fuji', the starch content decreased in proportion to the storage time. The starch degradation of 1-MCP-treated fruits was consistently low, but it did not definitely differ from the control (Fig. 2A). The respiration rate of all the fruits decreased during storage, with 1-MCP treatment being lowest at days 4-8. There was no difference in the respiration rate between ethylene-treated fruit and the control (Fig. 2B). Ethylene production was too low to calculate reliably with our measuring system during investigation of the fruits of all treatments. 

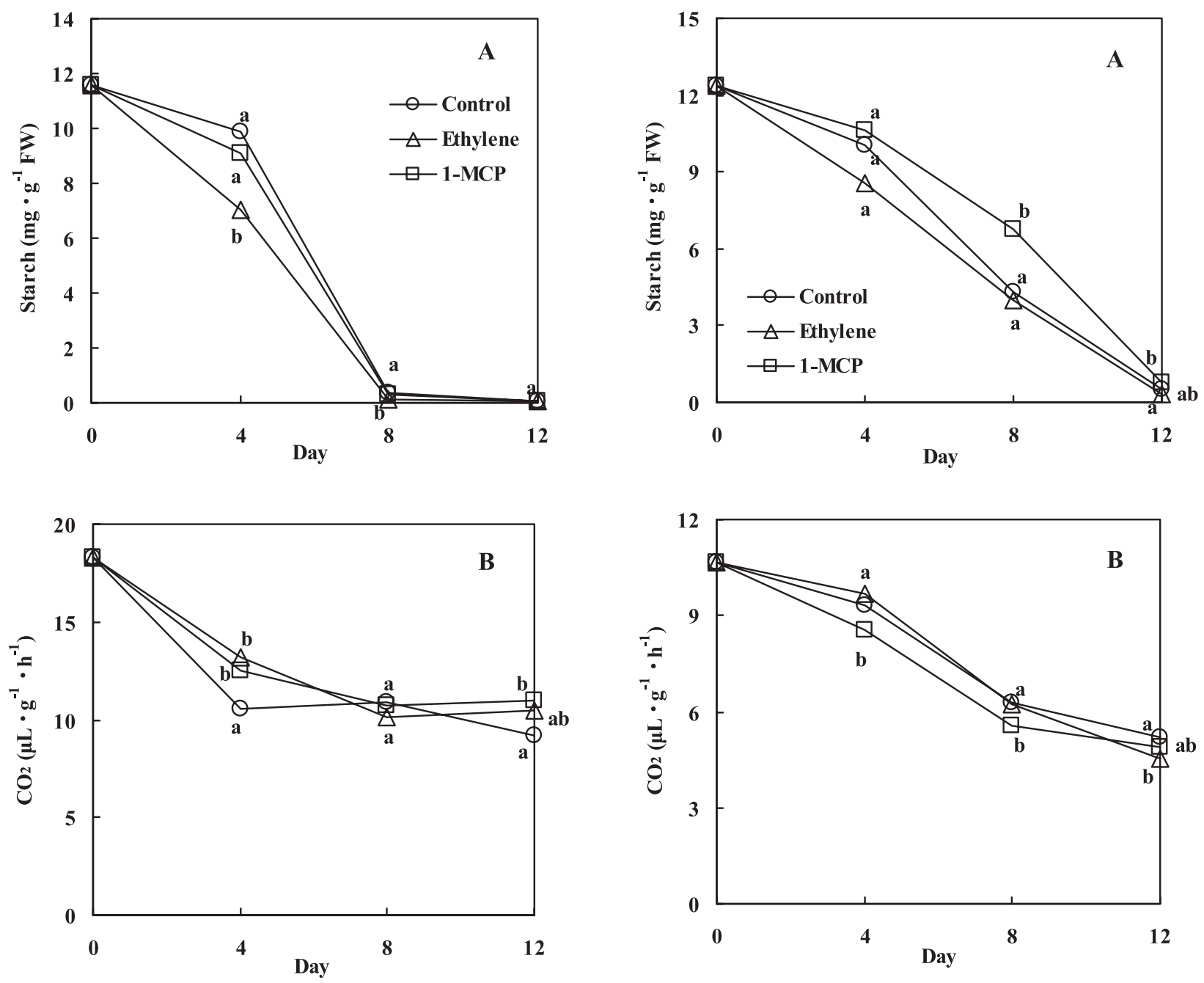

Fig. 1. Effects of ethylene and 1-MCP treatments on the starch content (A) and respiration rate (B) of immature 'Tsugaru' apples. Each value is the mean of five replicates. Means with the same letter are not significantly different at the $5 \%$ level by Tukey's multiple-range test.

\section{The effect of ethylene and 1-MCP on starch degradation in mature apple fruit}

The starch content of ethylene-treated 'Tsugaru' fruit decreased from day 4 to day 12 , and was significantly different from 1-MCP-treated fruit $(P \leq 0.05)$. Ethylene treatment enhanced starch degradation and lower starch content was observed in ethylene-treated fruit on day 4. The remaining starch content of 1-MCP-treated fruit was significantly higher than the control fruit, while the loss of starch in 1-MCP-treated fruit was observed during the investigation (Fig. 3A). Ethylene treatment promoted ethylene production and the respiration rate on days 4-8. 1-MCP treatment completely inhibited both changes on days $8-12$ (Fig. 3B, $\mathrm{C} ; P \leq 0.05$ ).

In mature 'Fuji', the starch content drastically decreased 4 days after treatment. Although the starch content of 1-MCP-treated fruit was slightly higher than the control on day 8 , it did not differ from the control on day 4 or 12 . The starch content of ethylene-treated

Fig. 2. Effects of ethylene and 1-MCP treatments on the starch content (A) and respiration rate (B) of immature 'Fuji' apples. Each value is the mean of five replicates. Means with the same letter are not significantly different at the $5 \%$ level by Tukey's multiple-range test.

fruit was not significantly different from the control during the experiment (Fig. 4A). The ethylene production of 1-MCP-treated fruit remained low. It was significantly lower than the control fruit on day 8 , but there was no difference when comparing ethylene treatment with the control (Fig. 4B). The respiration rate increased in the control and ethylene-treated fruit; however, no difference between these treatments was observed (Fig. 4C; $P \leq$ $0.05)$.

\section{Discussion}

The starch content decreases in association with fruit ripening on and off the tree (Brookfield et al., 1997; Lau, 1988; Magein and Leurquin, 2000; Watkins, 2003), and the starch content of the fruit is used as a maturity index of apple fruit. The loss of apple starch seems highly related to fruit climacteric and physiological changes such as increasing ethylene production and respiration rate; however, there is no clear report 

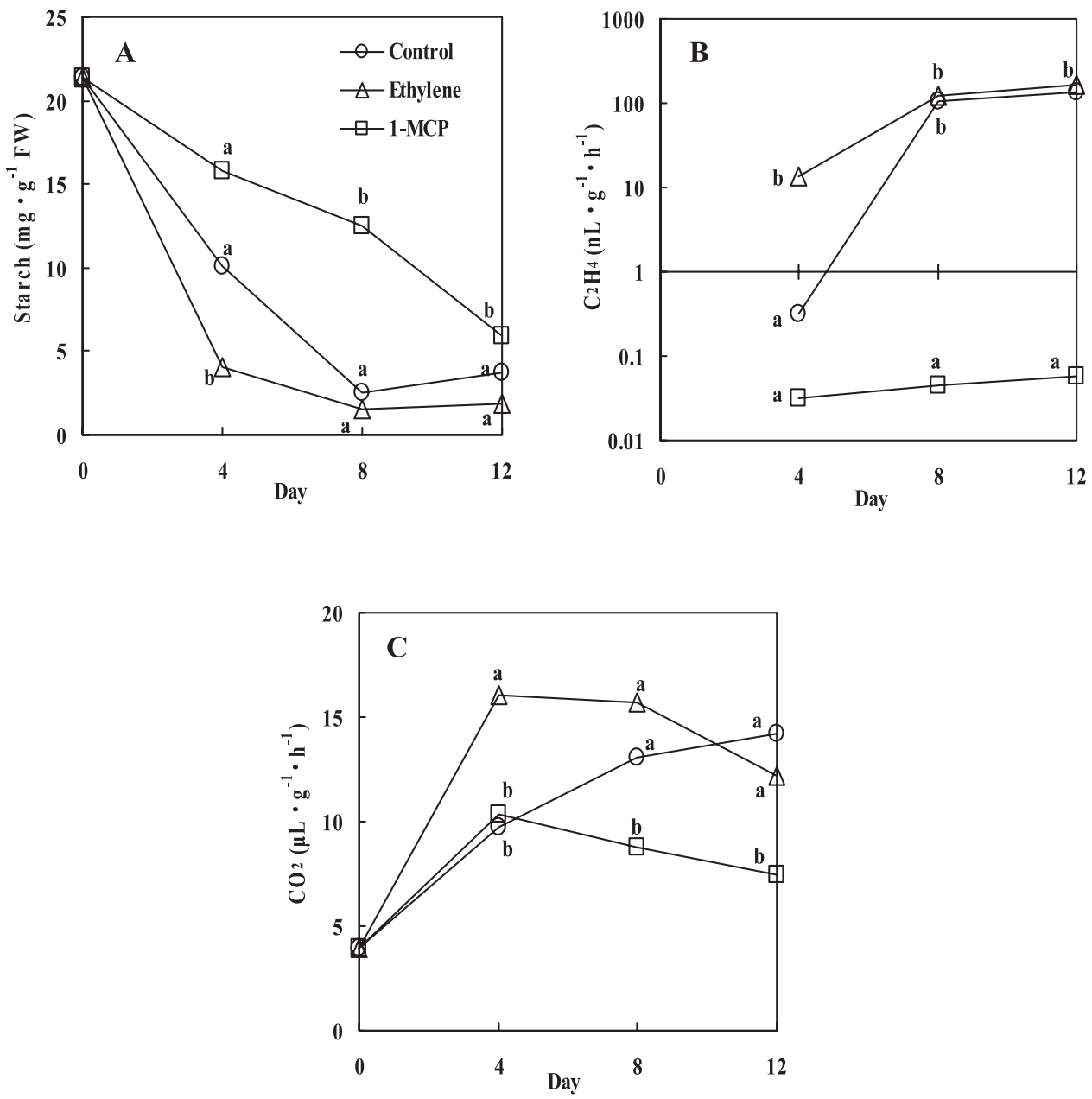

Fig. 3. Effects of ethylene and 1-MCP treatments on the starch content (A), ethylene production (B), and respiration rate (C) of mature 'Tsugaru' apples. Each value is the mean of four replicates. Means with the same letter are not significantly different at the 5\% level by Tukey's multiple-range test.

examining how the maturity of fruit affects starch degradation and fruit ripening physiology.

In the case of immature fruit, the starch of 'Tsugaru' and 'Fuji' rapidly decreased after harvest, while respiration gradually fell and ethylene production was low. Moreover, the effects of ethylene and 1-MCP on starch degradation were very small; the starch disappeared within 8 days after harvest for 'Tsugaru' and 12 days for 'Fuji', irrespective of the treatment. Although the fruit at this stage produced a low basal rate of ethylene, 1-MCP had no effect on starch degradation. These results showed that starch degradation at this stage did not relate to the climacteric of the fruit and ethylene. It seems that immature fruit could not respond to endogenous and exogenous ethylene.

Although it has been reported that the respiration rate of immature fruit decreases after harvest (McGlasson and Pratt, 1964; Zauberman and Schiffmann-Nadel; 1972); there is no clear explanation for this change. As fruits treated with ethylene had a higher respiration rate and lower starch content, it seems that starch degradation is partially related with respiration.
For mature fruit, the relation between starch degradation and the climacteric was different between 'Tsugaru' and 'Fuji'. In mature 'Tsugaru', ethylene treatment promoted the respiration rate and ethylene production, and 1-MCP treatment retarded both changes. In 'Fuji', although the respiration rate was inhibited by 1-MCP treatment, ethylene treatment had no effect on the production of ethylene and respiration. Moreover, although 1-MCP treatment clearly retarded starch degradation in 'Tsugaru', the effect was very low in 'Fuji'. It was suggested that starch degradation in 'Tsugaru' was related to the fruit climacteric, and ethylene has an important role in this metabolism. It seems that ethylene is not involved in the starch degradation of 'Fuji'. The starch content of 'Tsugaru' increased with the growth of fruit, and the level of starch in 'Tsugaru' was much higher than that of 'Fuji'. The different efficacy of 1-MCP on starch degradation between mature 'Tsugaru' and 'Fuji' might be due to this different starch level, but further research is needed.

Blankenship and Unrath (1988) found that starch degradation started before the increase in the internal 

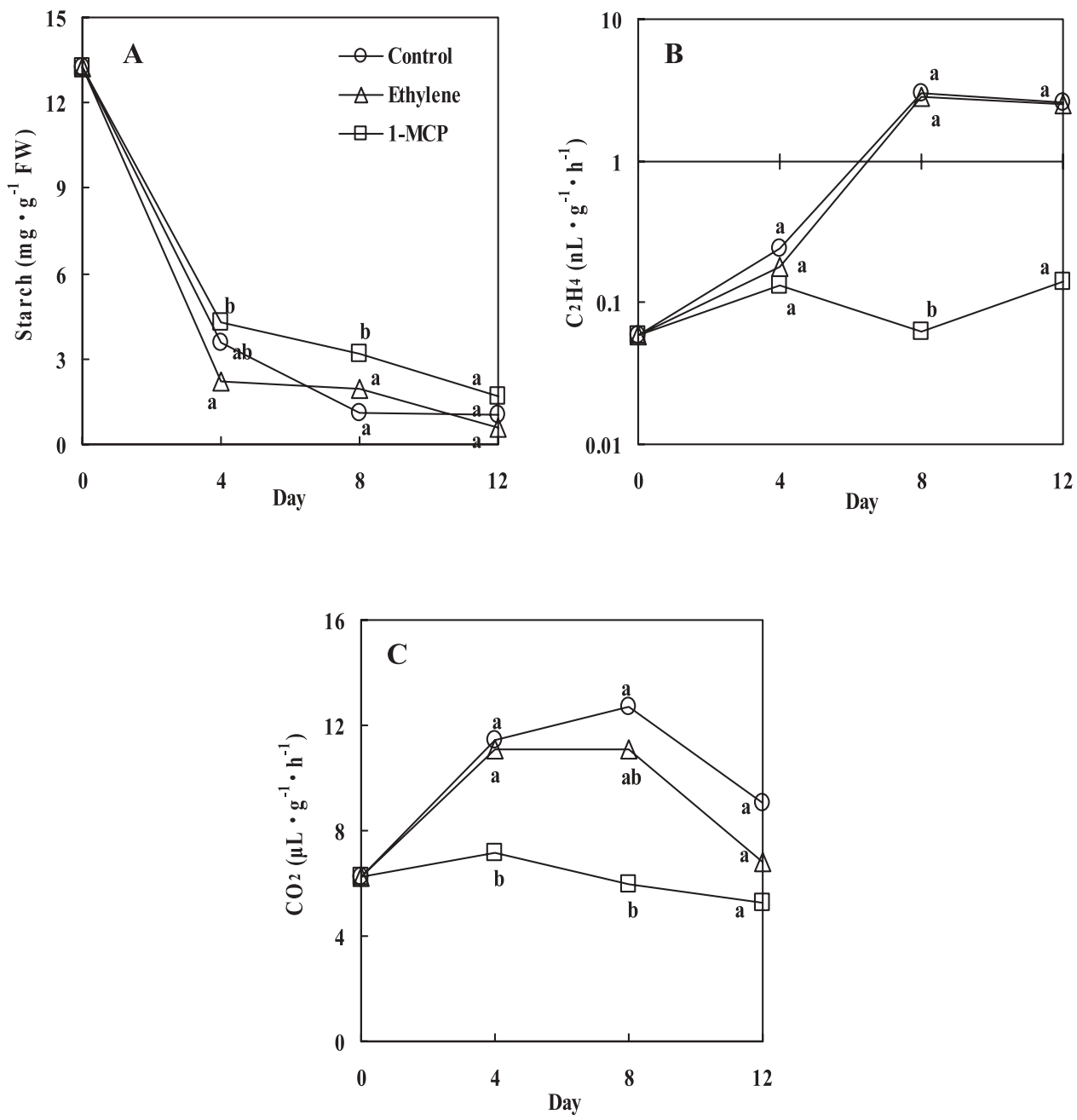

Fig. 4. Effects of ethylene and 1-MCP treatments on the starch content (A), ethylene production (B), and respiration rate (C) of mature 'Fuji' apples. Each value is the mean of four replicates. Means with the same letter are not significantly different at the $5 \%$ level by Tukey's multiple-range test.

ethylene concentration and suggested that ethylene is not the only factor inducing fruit ripening. Autio and Bramlage (1982) reported that pre-harvest treatment of the inhibitor of ethylene synthesis (AVG) in 'Early McIntosh', 'McIntosh', 'Cortland', and 'Royal Red Delicious' fruits retarded ethylene production, but there was no difference in the ripening aspects, including the starch content. Although 1-MCP strongly inhibits ethylene action, it has no effect on starch degradation during storage (Pre-Aymard et al., 2003; Rupasinghe et al., 2000; Watkins, 2006). Although these results suggested that ethylene plays a small role in starch degradation, our results showed that ethylene is partially involved in starch degradation in mature 'Tsugaru'.

It is well known that changes in the respiration rate and ethylene production are different among cultivars. While 'Tsugaru' produces a high amount of ethylene during ripening, 'Fuji' is known as a cultivar which produces a small amount of ethylene during ripening on the tree. It can be presumed that the role of ethylene in fruit ripening physiology, such as starch degradation, might differ between 'Tsugaru' and 'Fuji', because the starch content decreases during ripening before harvest in both cultivars.

It has been suggested that the loss of starch in the apple fruits is based on the action of enzymes, such as amylase (Beck and Ziegler, 1989; Frenkel et al., 1968; Garcia and Lajolo, 1988; Jackson, 2003; Zhang and Wang, 2002); however, the factors inducing the gene expression of the enzymes and enzyme activities are still unknown. From this study, it is particularly interesting that the degradation of starch during the immature stage occurred without increases in the respiration rate and ethylene production. It seems that the detachment of fruit from the tree and cessation of carbohydrate translocation into the fruit induced the physiological change and starch degradation (Irving et al., 1999). While the mechanism is not known, it has long been recognized that the tree factor induces fruit ripening and may also trigger the onset of starch degradation. 


\section{Literature Cited}

Autio, W. R. and W. J. Bramlage. 1982. Effects of AVG on maturation, ripening, and storage of apples. J. Amer. Soc. Hort. Sci. 107: 1074-1077.

Beck, E. and P. Ziegler. 1989. Biosynthesis and degradation of starch in higher plants. Annu. Rev. Plant Physiol. Plant Mol. Biol. 40: 95-117.

Blankenship, S. M. and C. R. Unrath. 1988. Internal ethylene levels and maturity of 'Delicious' apples destined for prompt consumption. J. Amer. Soc. Hort. Sci. 113: 88-91.

Brookfield, P., P. Murphy, R. Harker and E. Macrae. 1997. Starch degradation pattern indices; interpretation and relationship to maturity. Postharvest Biol. Technol. 11: 23-30.

Dinar, M. and M. A. Stevens. 1981. The relationship between starch accumulation and soluble solids content of tomato fruits. J. Amer. Soc. Hort. Sci. 106: 415-418.

Fan, X., J. P. Mattheis and S. M. Blankenship. 1999. 1-Methylcyclopropene inhibits apple ripening. J. Amer. Soc. Hort. Sci. 124: 690-695.

Frenkel, C., I. Klein and D. R. Dilley. 1968. Protein synthesis in relation to ripening of pome fruits. Plant Physiol. 43: 11461153.

Garcia, E. and F. M. Lajolo. 1988. Starch transformation during banana ripening: the amylase and glucosidase behaviour. J. Food Sci. 53: 1181-1186.

Irving, D. E., G. J. Shingleton and P. L. Hurst. 1999. Starch degradation in butter squash (Cucurbita maxima). J. Amer. Soc. Hort. Sci. 124: 587-590.

Jackson, J. E. 2003. Eating quality and its retention. p. 341-383. In: J. E. Jackson (ed.). Biology of apples and pears. Cambridge Univ. Press, New York.

Kader, A. A. 1985. Ethylene-induced senescence and physiological disorders in harvested horticultural crops. HortScience 20: 54-57.

Lau, O. L. 1988. Harvest indices, dessert quality, and storability of 'Jonagold' apples in air and controlled atmosphere storage. J. Amer. Soc. Hort. Sci. 113: 564-569.

Magein, H. and D. Leurguin. 2000. Changes in amylase, amylopectin and total starch content in 'Jonagold' apple fruit during growth and maturation. Acta Hort. 517: 487-491.

McGlasson, W. B. and H. K. Pratt. 1964. Effects of ethylene on cantaloupe fruits harvested at various ages. Plant Physiol. 39: $120-127$.

Pharr, D. M. and H. N. Sox. 1984. Changes in carbohydrate and enzyme levels during the sink to source transition of leaves of Cucumis sativus L., a stachyose translocator. Plant Sci. Lett. 35: 187-193.

Prabha, T. N. and N. Bhagyalakshmi. 1998. Carbohydrate metabolism in ripening banana fruit. Phytochemistry 48: 915 919.

Pre-Aymard, C., A. Weksler and S. Lurie. 2003. Responses of 'Anna' rapidly ripening summer apple, to 1-methylcyclopropene. Postharvest Biol. Technol. 27: 163-170.

Rupasinghe, H. P. V., D. P. Murr, G. Paliyath and L. Skog. 2000. Inhibitory effect of 1-MCP on ripening and superficial scald development in 'McIntosh' and 'Delicious' apples. J. Hort. Sci. Biotech. 74: 271-276.

Sisler, E. C. and M. Serek. 1997. Inhibitors of ethylene responses in plants at the receptor level: Recent developments. Physiol. Plant. 100: 577-582.

Wang, Z., Z. Yuan and B. Quebedeaus. 1997. Photoperiod alters diurnal carbon partitioning into sorbitol and other carbohydrates in apple. Aus. J. Plant Physiol. 24: 587-597.

Watkins, C. B. 2003. Principles and practices of postharvest handling and stress. p. 585-614. In: D. C. Ferree and I. J. Warrington (eds.). Apples: Botany, production and uses. CABI Publishing, Massachusetts.

Watkins, C. B. 2006. The use of 1-methylcycloprppene (1-MCP) on fruits and vegetables. Biotech. Adv. 24: 389-409.

Zauberman, G. and M. Schiffmann-Nadel. 1972. Respiration of whole fruit and seed of avocado at various stages of development. J. Amer. Soc. Hort. Sci. 97: 313-315.

Zhang, D. and Y. Wang. 2002. $\beta$-amylase in developing apple fruits: activities, amounts and subcellular localization. Sci. China (series C). 45: 429-440. 